\title{
Inhibition of Akt activity induces the mesenchymal-to-epithelial reverting transition with restoring $E$-cadherin expression in $K B$ and KOSCC-25B oral squamous cell carcinoma cells
}

\author{
Kyoung-Ok Hong, Ji-Hong Kim, Ji-Soo Hong, Hye-Jung Yoon, Jae-Il Lee, \\ Sam-Pyo Hong and Seong-Doo Hong*
}

Address: Department of Oral Pathology, School of Dentistry and Dental Research Institute, Seoul National University, Seoul, Korea

Email: Kyoung-Ok Hong - hongko95@hanmail.net; Ji-Hong Kim - omfshong@nate.com; Ji-Soo Hong - sentijs7@snu.ac.kr; HyeJung Yoon - enprism1@snu.ac.kr; Jae-Il Lee - jilee@snu.ac.kr; Sam-Pyo Hong - hongsp@snu.ac.kr; Seong-Doo Hong* - hongsd@snu.ac.kr

* Corresponding author

Published: 26 February 2009

Journal of Experimental \& Clinical Cancer Research 2009, 28:28 doi:10.1 I86/1756-9966-28-28

This article is available from: http://www.jeccr.com/content/28/I/28

(C) 2009 Hong et al; licensee BioMed Central Ltd.

This is an Open Access article distributed under the terms of the Creative Commons Attribution License (http://creativecommons.org/licenses/by/2.0), which permits unrestricted use, distribution, and reproduction in any medium, provided the original work is properly cited.

\begin{abstract}
Background: The Akt/PKB family of kinases is frequently activated in human cancers, including oral squamous cell carcinoma (OSCC). Akt-induced epithelial-to-mesenchymal transition (EMT) involves downregulation of E-cadherin, which appears to result from upregulation of the transcription repressor Snail. Recently, it was proposed that carcinoma cells, especially in metastatic sites, could acquire the mesenchymal-to-epithelial reverting transition (MErT) in order to adapt the microenvironments and re-expression of E-cadherin be a critical indicator of MErT. However, the precise mechanism and biologic or clinical importance of the MErT in cancers have been little known. This study aimed to investigate whether Akt inhibition would restore the expression of E-cadherin and $\beta$-catenin, reduce that of Vimentin, and induce the MErT in OSCC cells with low or negative expression of E-cadherin. We also investigate whether inhibition of Akt activity would affect the E-cadherin repressors and signaling molecules like NF- $\mathrm{B}$, ERK, and p38.
\end{abstract}

Methods: We screened several OSCC cell lines in order to select suitable cell line models for inducing MErT, using immunoblotting and methylation specific-PCR. We examined whether Akt inhibitor phosphatidylinositol ether lipid analogues (PIA) treatment would restore the expression of E-cadherin and $\beta$-catenin, reduce that of Vimentin, and induce the MErT in KB and KOSCC-25B cells using RT-PCR, immunoblotting, immunofluorescence analysis, and in vitro migration assay. We also investigated whether inhibition of Akt activity would affect the E-cadherin repressors, including Snail, Twist, and SIP-I/ZEB-2 and signaling molecules like NF- $\kappa B$, ERK, JNK, and p38 using RT-PCR, immunoblotting, and immunofluorescence analysis.

Results: Of the 7 OSCC cell lines, KB and KOSCC-25B showed constitutively activated phosphorylated Akt and low or negative expression of E-cadherin. Inhibition of Akt activity by PIA decreased NF- $\kappa$ B signaling, but did not affect phosphorylation of ERK, JNK, and p38 in KB and KOSCC-25B cells. Akt inhibition led to downregulation of Snail and Twist expression. In contrast, inhibition of Akt activity by PIA did not induce any changes in SIP-I/ZEB-2 expression. PIA treatment induced the expression of E-cadherin and $\beta$-catenin, reduce that of Vimentin, restored their epithelial morphology of a polygonal shape, and reduced tumor cell migration in KB and KOSCC-25B cells, which was the corresponding feature of MErT.

Conclusion: All of these findings suggest that Akt inhibition could induce the MErT through decreased NF- $\mathrm{B}$ signaling and downregulation of Snail and Twist in OSCC cells. A strategy involving Akt inhibition might be a useful therapeutic tool in controlling cancer dissemination and metastasis in oral cancer patients. 


\section{Background}

Oral squamous cell carcinoma (OSCC) is the most common neoplasm of the head and neck. Carcinoma cells accumulate a series of genetic and/or epigenetic changes and altered phenotypes during tumor progression. Loss of epithelial morphology and acquisition of mesenchymal characteristics, termed the epithelial-to-mesenchymal transition (EMT), are typical for carcinoma cells during tumor progression and correlate with the local invasiveness and metastatic potential of the tumor [1,2]. Among the mechanisms largely associated with the metastatic conversion of epithelial cells and the EMT, the loss of Ecadherin-mediated cell adhesion is prominent $[3,4]$.

The Akt/PKB family of kinases is a downstream effector of phosphatidylinositol 3-kinase (PI3K) and is frequently activated in human cancers, including OSCC [5-8]. Recently, activation of the PI3K/Akt axis is emerging as a central feature of EMT. Akt-induced EMT involves downregulation of E-cadherin, which appears to result from upregulation of the transcription repressor Snail. Akt activity is induced by ligand stimulation of growth factor receptors such as the insulin-like growth factor-I receptor (IGF-IR) and the EGF family of receptors [9]. Ligand stimulation activates PI3K, the upstream activator of Akt, by direct binding to either the activated phosphorylated receptor or to adaptor proteins phosphorylated by receptor kinase activity [10]. Phosphoinositides generated by PI3K activity trigger activation of Akt kinases through direct binding to the pleckstrin homology $(\mathrm{PH})$ domain and the subsequent phosphorylation of Akt at two conserved residues [11]. Therefore, we used an Akt inhibitor, structurally modified phosphatidylinositol ether lipid analogues (PIA) [12], that specifically binds to the $\mathrm{PH}$ domain of Akt.

Recently, it was proposed that carcinoma cells, especially in metastatic sites, could acquire the mesenchymal-to-epithelial reverting transition (MErT) in order to adapt the microenvironments and re-expression of E-cadherin be a critical indicator of MErT $[13,14]$. Therefore, it seems to be important to investigate which molecules or inhibitors could induce MErT in cancers. However, the precise mechanism and biologic or clinical importance of the MErT in cancers have been little known in in vitro and in vivo study.

The purpose of our study was to investigate whether Akt inhibition by PIA treatment would restore the expression of E-cadherin and $\beta$-catenin, reduce that of Vimentin, and induce the MErT in OSCC cells with low or negative expression of E-cadherin. We also investigated whether inhibition of Akt activity would affect the E-cadherin repressors, including Snail, Twist, and SIP-1/ZEB-2 and signaling molecules like NF- $\mathrm{B}, \mathrm{ERK}, \mathrm{JNK}$, and p38.

\section{Materials and methods \\ Cell culture and reagents}

KB, SCC-15, SCC-25 (American Type Culture Collection, Manassas, VA), HSC-3, HSC-4, Ca9-22 (from Dr. T. Takata, Hiroshima Univ.), and KOSCC-25B (from Dr. BM Min, Seoul National Univ.) [15,16] human OSCC cells were cultured in DMEM supplemented with 10\% fetal bovine serum (FBS) and antibiotics $(100 \mathrm{U} / \mathrm{ml}$ penicillin and $100 \mu \mathrm{g} / \mathrm{ml}$ streptomycin). Akt inhibitor PIA (SH-5) was purchased from Calbiochem (Gibbstown, NJ). Antibodies against Akt1/2, phosphorylated ERK (Tyr 204), phosphorylated JNK (Thr183/Tyr185), phosphorylated p65, p50, p38, Snail, SIP-1/ZEB-2, Twist, $\beta$-catenin, and Ecadherin were purchased from Santa Cruz Biotechnology (Santa Cruz, CA). Phosphorylated Akt (Ser 473) was obtained from Cell Signaling Technology (Danvers, MA). Vimentin was obtained from BD Biosciences (Franklin Lakes, NJ). $\alpha$-Tubulin and phalloidin-TRITC were purchased from Sigma (St. Louis, MO).

\section{Pharmacological Treatments}

OSCC cells were plated at $2-2.5 \times 10^{5}$ cells/well in 6 - or 12-well plates in DMEM containing 10\% FBS and incubated for $24 \mathrm{~h}$. The medium was then changed to DMEM with $0.1 \%$ FBS, and the cells were incubated overnight. After overnight incubation, cells were treated with PIA dissolved in DMSO ( $5 \mu \mathrm{M})$ for $12 \mathrm{~h}$ (in vitro migration assay) or $24 \mathrm{~h}$ (other experiments). In all experiments, DMSO added to control samples had no effect on Akt activity.

\section{RT-PCR}

mRNA was purified from the cells using the Trizol reagent (Invitrogen, Carlsbad, CA) according to the manufacturer's recommended protocol. Two $\mu \mathrm{g}$ RNA was added to RT-PCR reactions containing primers at a concentration of $0.5 \mu \mathrm{M}$. After a $42^{\circ} \mathrm{C} / 60$-min reverse transcription step, 30 cycles of PCR amplification were performed at $94^{\circ} \mathrm{C}$ for $30 \mathrm{sec}, 58^{\circ} \mathrm{C}$ for $50 \mathrm{sec}$, and $72^{\circ} \mathrm{C}$ for $50 \mathrm{sec}$. PCR products were run on $1.5 \%$ agarose gels for identification. Primers used were 5'-TCC CAT CAG CTG CCCAGA AA-3' and 5'-TGA CTC CTG TGT TCC TGT TA-3' for E-cadherin, 5'-AAG CAG GAG TCC ACT GAG TA-3' and 5'-GTA TCA ACC AGA GGG AGT GA-3' for Vimentin, 5'-GGG CAG GTA TGG AGA GGA AGA-3' and 5'-TTC TTC TGC GCT ACT GCT GCG-3' for Snail, 5'-TTC CTG GGC TAC GAC CAT AC-3' and 5'-GCC TTG AGT GCT CGA TAA-3' for Sip1, 5'-GGA GTC CGC AGT CTT ACG AG-3' and 5'-TCT GGA GGA CCT GGT AGA GG-3' for Twist, 5'-GCT GAT TTG ATG GAG TTG GA-3' and 5'-GCT ACT TGT TCT TGA GTG AA-3' for $\beta$-catenin, and 5'-GAA GGT GAA GGT CGG AGT C-3' and 5'-CAA AGT TGT CAT GGA TGA CC-3' for GAPDH. 


\section{Analysis of the E-cadherin promoter by Methylation specific-PCR (MS-PCR)}

Methylation status of the CpG sites in the E-cadherin promoter region was analyzed based on the principle that bisulfite modification of the genomic DNA would convert unmethylated cytosine residues to uracil, whereas methylated cytosine is resistant to the treatment. Bisulfite modification and MS-PCR were carried out as described $[17,18]$. Modified DNA was amplified using primers specific for the methylated sequence (5'-TTA GGT TAG AGG GTT ATC GCG T-3' and 5'-TAA CTA AAA ATT CAC CTA CCG AC-3' and for the unmethylated sequence (5'-TAA TTT TAG GTT AGA GGG TTA TTG T-3' and 5'-CAC AAC CAA TCA ACA ACA CA-3'). 35 cycles of PCR amplification were performed at $94^{\circ} \mathrm{C}$ for $30 \mathrm{sec}, 56^{\circ} \mathrm{C}$ for $30 \mathrm{sec}$, and $72^{\circ} \mathrm{C}$ for $30 \mathrm{sec}$. PCR products were run on $2 \%$ agarose gels for identification. MDA-MB-231 and MCF-7 (American Type Culture Collection) breast cancer cells were utilized as positive controls for methylated and unmethylated E-cadherin gene, respectively [19].

\section{Immunoblotting}

Briefly, 70-80\% confluent cells were homogenized with 1 $\mathrm{ml}$ of lysis buffer (10 mM HEPES, pH 7.9, $1.5 \mathrm{mM} \mathrm{MgCl}_{2}$, $10 \mathrm{mM} \mathrm{KCl}, 0.5 \mathrm{mM}$ DTT, $0.2 \mathrm{mM}$ PMSF) and incubated on ice. To the homogenates was added $125 \mu$ of $10 \%$ NP40 solution, and the mixture was then centrifuged for 30 $\mathrm{sec}$ at $12,000 \times \mathrm{g}$. Supernatant protein concentration was determined by the Bradford protein assay (Bio-Rad, Hercules, CA, USA) using bovine serum albumin (Sigma) as a standard. Immunoblot analysis was performed as described elsewhere [20].

\section{Immunofluorescence analysis and confocal microscopy} Cells grown on coverslips were fixed in 4\% PFA, permeabilized in $0.3 \%$ Triton X-100, and blocked for $40 \mathrm{~min}$ in $1 \% \mathrm{BSA} / 10 \%$ fetal bovine serum. The cell samples were incubated with primary antibodies at $4{ }^{\circ} \mathrm{C}$ overnight, washed with PBS containing $0.1 \%$ BSA, and then reacted with FITC- or Cy3-conjugated secondary antibodies (Jackson ImmunoResearch Laboratories, West Grove, PA, USA) at room temperature for $40 \mathrm{~min}$. After washing, the samples were rinsed with PBS containing 0.1\% BSA, stained with $5 \mathrm{mg} / \mathrm{ml}$ 4,6-diamidino-2-phenylindole (DAPI; Sigma), and mounted. Confocal analyses were performed using an Olympus (Center Valley, PA) FC-300 Confocal Laser Scanning Microscope equipped with FITC- and Cy3channel filter systems. All images were converted to TIFF format and arranged using Photoshop 7.0 (Adobe, Seattle, WA).

\section{In vitro migration assay}

The in vitro migration assay was performed as described previously [21]. $5 \times 10^{4}$ cells were placed in the upper compartment ( $8 \mu \mathrm{m}$ pore size) of the cell culture insert with or without $5 \mu \mathrm{M}$ PIA. Medium, supplemented with $100 \mathrm{ng} / \mathrm{ml}$ IGF-I (R\&D Systems, Minneapolis, MN), was added to the lower compartment. After $12 \mathrm{~h}$ of incubation, the cells on the upper surface of the filter were wiped out with a cotton swab, and the filter was removed from the chamber and stained with Diff-Quick stain set (Fisher, Pittsburgh, PA). The migration of the cells was determined by counting the number of cells that migrated through the pores to the lower side of the filter under a microscope at $100 \times$ magnification. We performed the assay three times, and three randomly selected fields were counted for each assay. We used Student's $t$ test to determine the significance at a level of $P<0.05$.

\section{Results}

\section{Screening of oral squamous cell carcinoma cell lines}

We screened several OSCC cell lines in order to select suitable cell line models with the characteristics of the EMT (low or negative expression of E-cadherin) and a constitutively activated state of Akt. Of the 7 OSCC cell lines, $\mathrm{KB}$, KOSCC-25B, Ca9-22, and SCC-15 showed constitutively activated phosphorylated Akt (p-Akt). Of these four lines, only KB and KOSCC-25B showed low or negative expression of E-cadherin (Fig. 1A). Because the E-cadherin downregulation could be caused by the methylation of its promoter, we investigated the methylation status of E-cadherin gene promoter in the KB and KOSCC-25B cells with MS-PCR. PCR products were detected in both $\mathrm{KB}$ and KOSCC-25B with unmethylation-specific primer pairs, not methylation-specific ones (Fig. 1B). These results indicate that the $\mathrm{KB}$ and KOSCC-25B have unmethylated $\mathrm{E}$ cadherin gene. So, the KB and KOSCC-25B cell lines were chosen as suitable models for the present study.

\section{Effects on Akt and Akt-related signaling molecules by PIA treatment}

As expected, there were no changes in Akt 1 and Akt 2 protein levels in KB and KOSCC-25B cells and p-Akt level was significantly lower after $5 \mu \mathrm{M}$ PIA treatment for 24 hours (Fig. 2A). However, ILK, upstream molecules of Akt, did not show any change after PIA treatment, indicating that PIA is a specific blocker of Akt signaling. Next, we investigated whether PIA treatment could affect signaling molecules such as ERK, p38, p50, and p65. Inhibition of Akt activity by PIA induced downregulation of p-p65 and p50 , but did not affect phosphorylation of ERK, JNK, and p38 in KB and KOSCC-25B cells (Fig. 2B).

\section{Effects of Akt inhibition on Snail, SIP-I/ZEB-2, and Twist expression}

We examined the effects of Akt inhibition on the expression of EMT-related transcription factors Snail, SIP-1/ZEB2, and Twist in KB and KOSCC-25B cells. Downregulation of Snail and Twist was detected by immunoblot and RTPCR analysis (Fig. 3A). In addition, a shift from the 

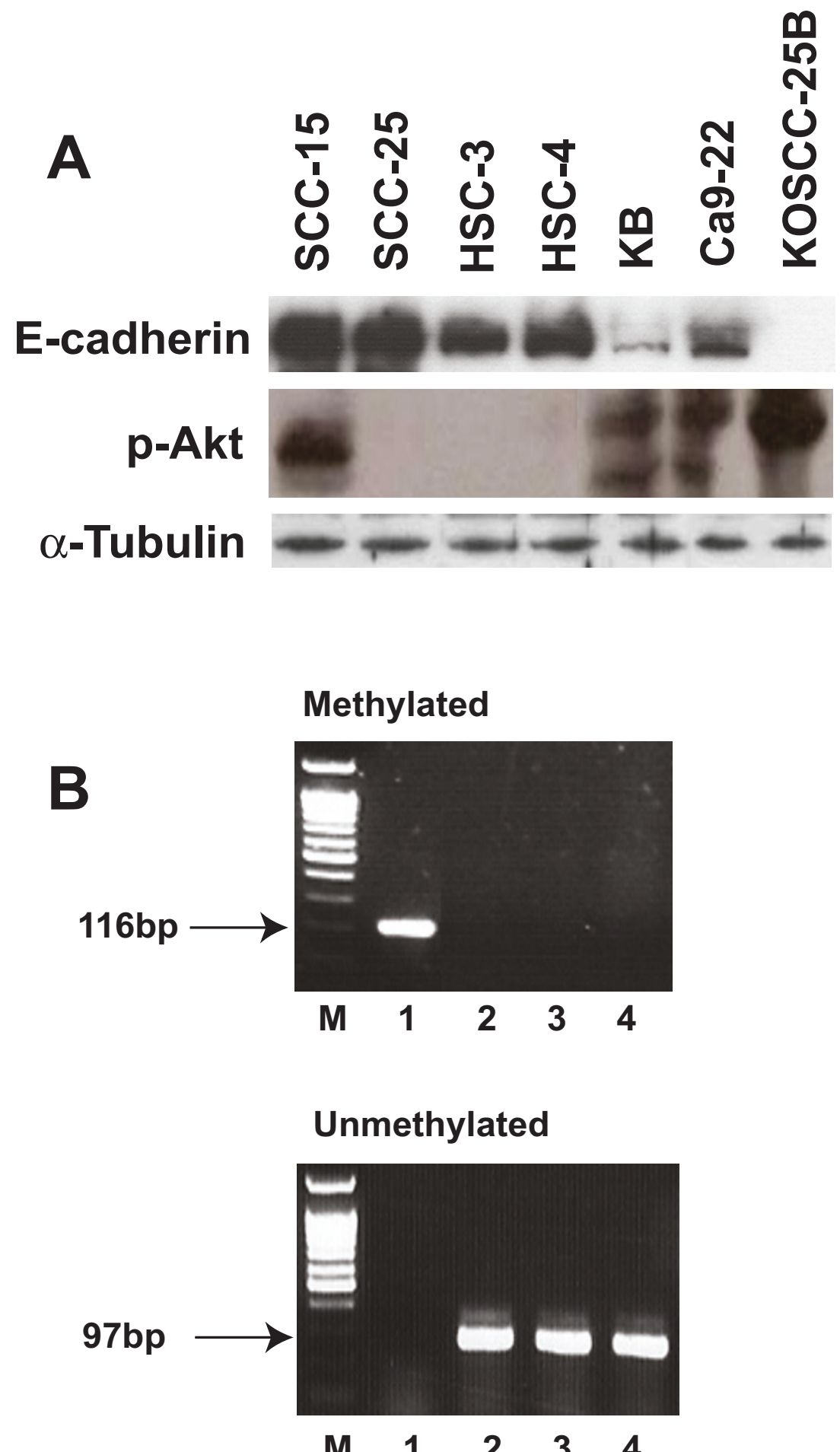

Figure I

Screening of OSCC cell lines in order to obtain a suitable cell line model for inducing MErT. (A) Of the 7 OSCC cell lines, KB, KOSCC-25B, Ca9-22, and SCC-15 showed constitutively activated phosphorylated Akt (p-Akt). Of these four lines, only KB and KOSCC-25B showed low or negative expression of E-cadherin. (B) Methylation specific-PCR: PCR products were detected in both $K B$ and $K O S C C-25 B$ with unmethylation-specific primer pairs, not methylation-specific ones. M, DNA ladder; lane I, MDA-MB-23I; lane 2, MCF-7; lane 3, KB; lane 4, KOSCC-25B. 

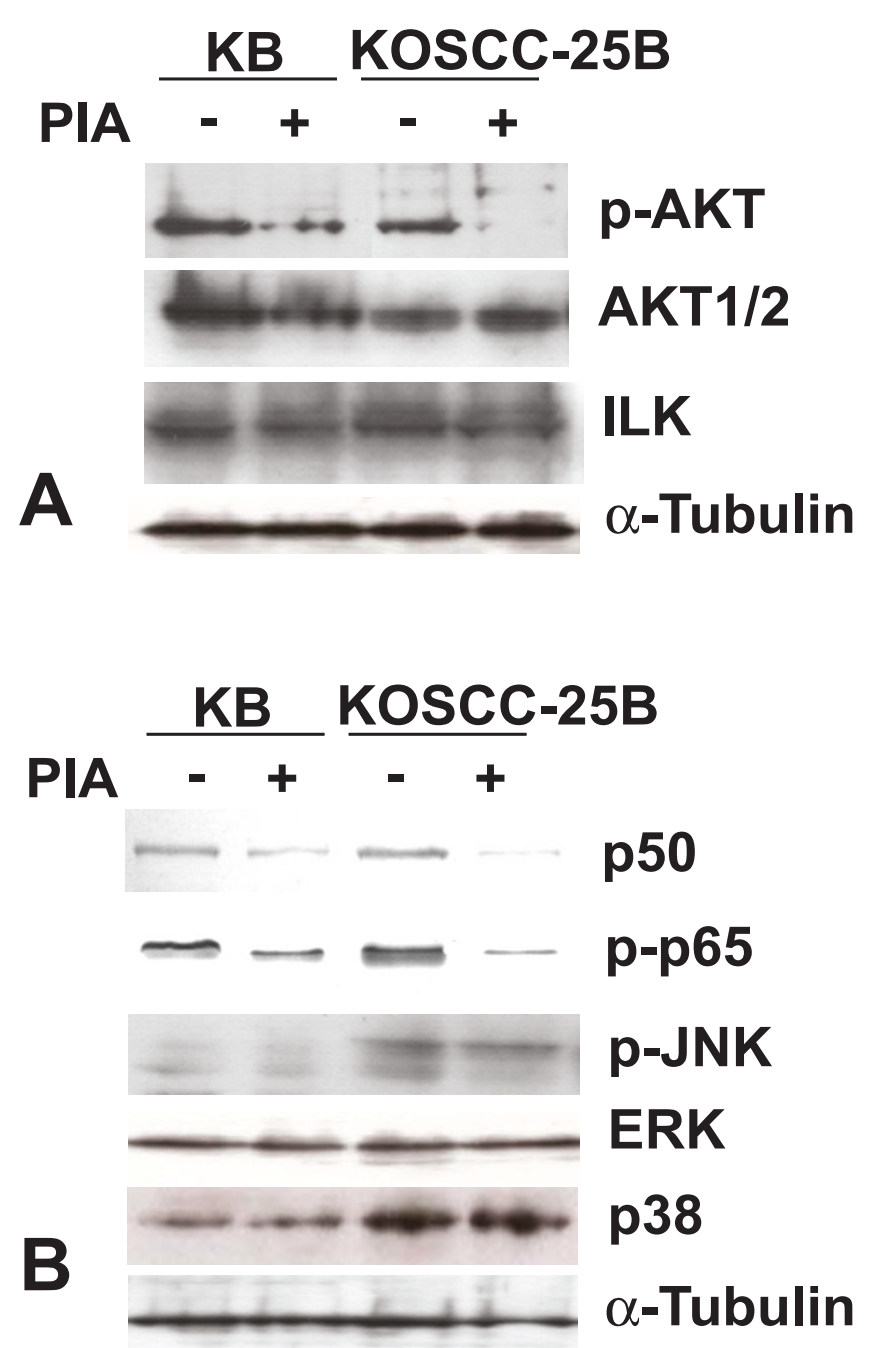

Figure 2

Effects of PIA treatment on Akt and Akt-related signaling molecules. (A) P-Akt level in KB and KOSCC-25B cells was significantly lower after $5 \mu \mathrm{M}$ PIA treatment for 24 hours. However, Akt I/2 and ILK (upstream molecules of Akt) did not show any change after PIA treatment. (B) Inhibition of Akt activity by PIA induced downregulation of $\mathrm{p} 50$ and $\mathrm{p}$-p65 in KB and KOSCC-25B cells, but it did not affect phosphorylation of JNK, p38, and ERK.

nucleus to the cytoplasm of Snail and Twist was detected in the immunofluorescence analysis (Fig. 3B). In contrast, inhibition of Akt activity by PIA did not induce any changes in SIP-1/ZEB-2 expression.

\section{Effects of Akt inhibition on epithelial and mesenchymal markers}

KOSCC-25B cells had an elongated shape, assuming a fibroblast-like appearance. In contrast, PIA treatment of the cells seemed to restore their epithelial morphology of a polygonal shape (Fig. 4A upper panel). In phalloidin staining, KOSCC-25B cells demonstrated circumferential, cortical actin, and actin in elongated filopodia; however, no actin stress fibers were detected. In contrast, PIAtreated cells revealed an abudance of actin stress fibers (Fig. 4A lower panel). These results showed that PIA treatment of the cells induced actin cytoskeleton reorganization, which contributed to loss of the migratory phenotype. We examined whether PIA treatment could affect the expression and localization of E-cadherin and $\beta$ catenin, epithelial markers, and Vimentin, a mesenchymal marker. In accordance with the observed morphologic change, inhibition of Akt activity induced the expression in immunoblotting and RT-PCR (Fig. 4B) and localization of E-cadherin and $\beta$-catenin as seen in the immunofluorescence analysis (Fig. 5 upper and middle panel). Also, PIA treatment decreased the vimentin expression (Fig. 4B) or localization (Fig. 5 lower panel), although the change was not as prominent as that in the epithelial markers.

\section{Reduced migratory ability after Akt inhibition}

In order to examine whether inhibition of Akt activity could affect cell motility, we performed an in vitro migration assay. The numbers of KB and KOSCC-25B cells from the PIA-treated group that migrated through the filter were only $61.1 \%$ and $56.4 \%$ of that in control cells $(P<$ 0.05; Fig. 6), respectively.

\section{Discussion}

During EMT, epithelial cells acquire fibroblast-like properties and exhibit reduced cell-cell adhesion and increased motility. The plasticity afforded by the EMT is central to the complex remodeling of embryo and organ architecture during gastrulation and organogenesis. In pathological processes such as oncogenesis, the EMT may endow cancer cells with enhanced motility and invasiveness. Indeed, oncogenic transformation may be associated with signaling pathways promoting the EMT [22]. Akt activation is frequent in human epithelial cancer. In our previous study [23], Akt activation in OSCC was linked to aggressive clinical behavior and the loss of histological features of epithelial differentiation. These findings are consistent with Akt directly affecting epithelial cell morphology, cell motility, and invasiveness.

Grille et al. [24] demonstrated that OSCC cells engineered to express constitutively active Akt underwent EMT, characterized by downregulation of the epithelial markers desmoplakin, E-cadherin, and beta-catenin, and upregulation of the mesenchymal marker vimentin. The cells also lost their epithelial cell morphology and acquired fibroblast-like properties. In addition, the cells expressing constitutively active Akt exhibited reduced cell-cell adhesion, increased motility on fibronectin-coated surfaces, and increased invasiveness in animals. 

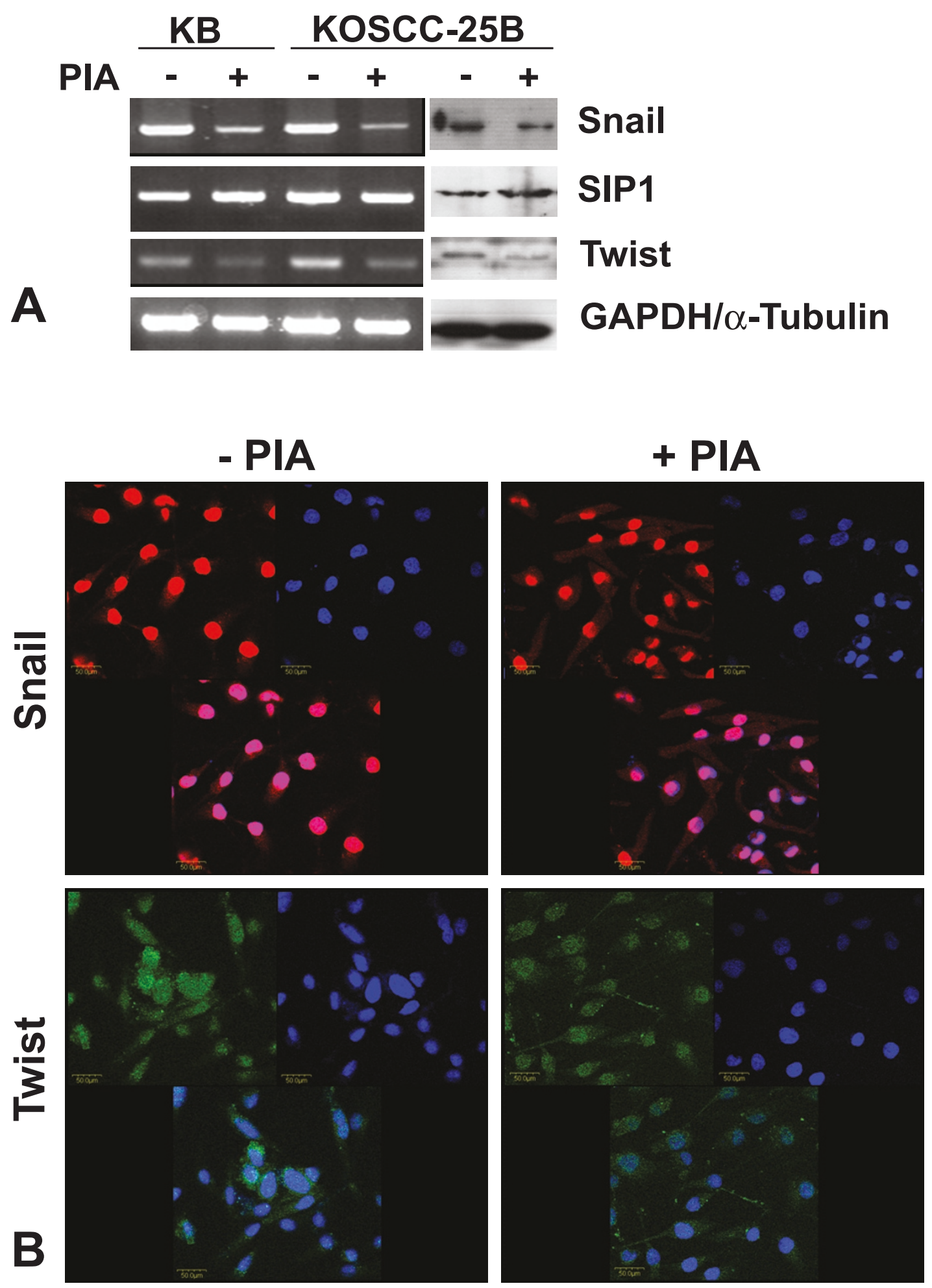

Figure 3

Effects of Akt inhibition on Snail I, SIP- I/ZEB-2, and Twist expression and localization. (A) Downregulation of Snail and Twist was detected in KB and KOSCC-25B cells by immunoblot and RT-PCR analysis. In contrast, inhibition of Akt activity by PIA did not induce any changes in SIP-I/ZEB-2 mRNA and protein expression. (B) A shift from the nucleus to the cytoplasm of Snail and Twist in KOSCC-25B cells was detected by immunofluorescence analysis. 
- PIA
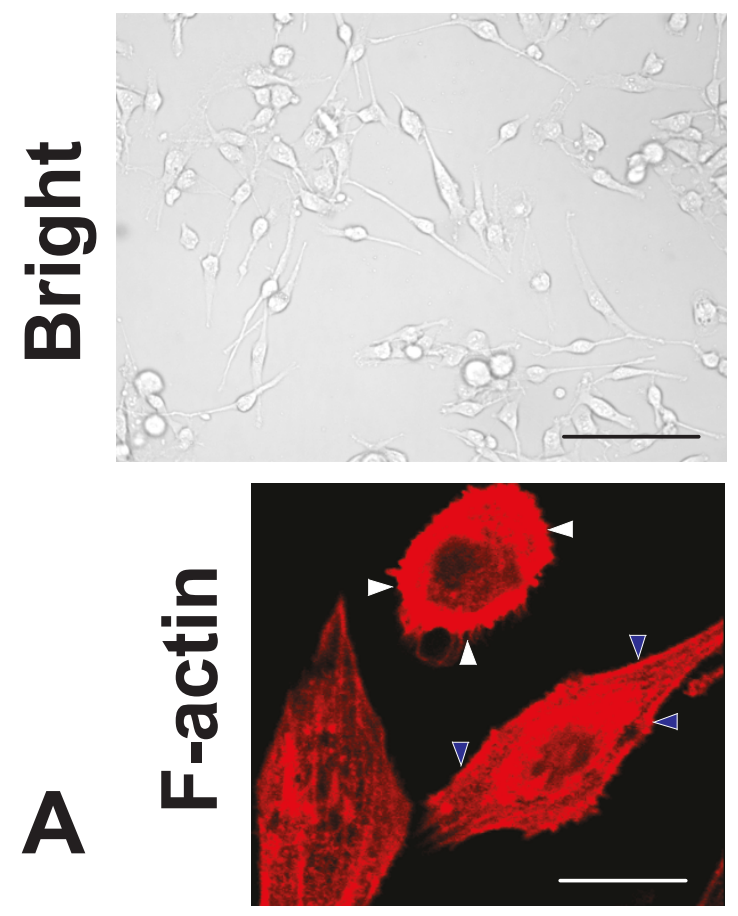

+ PIA
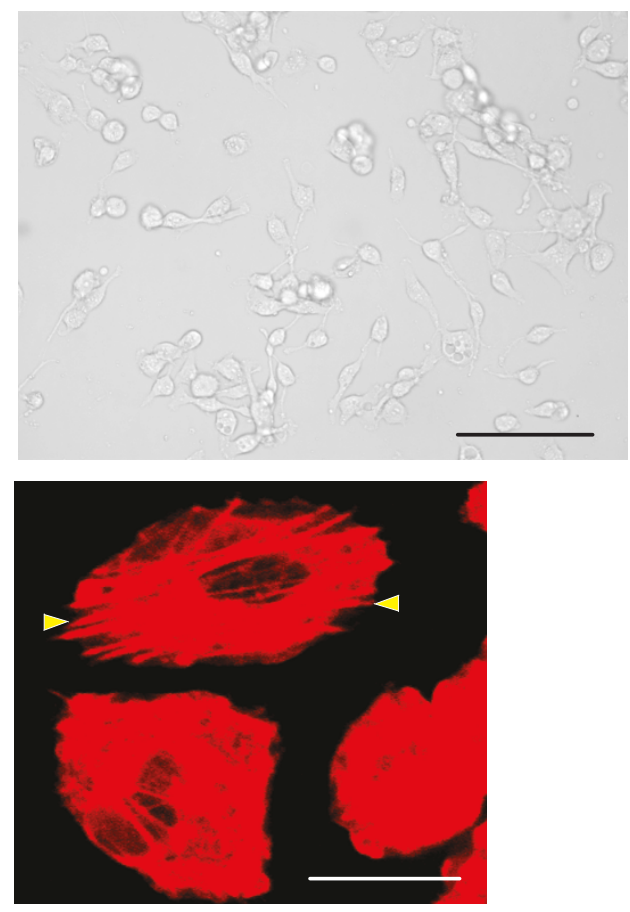

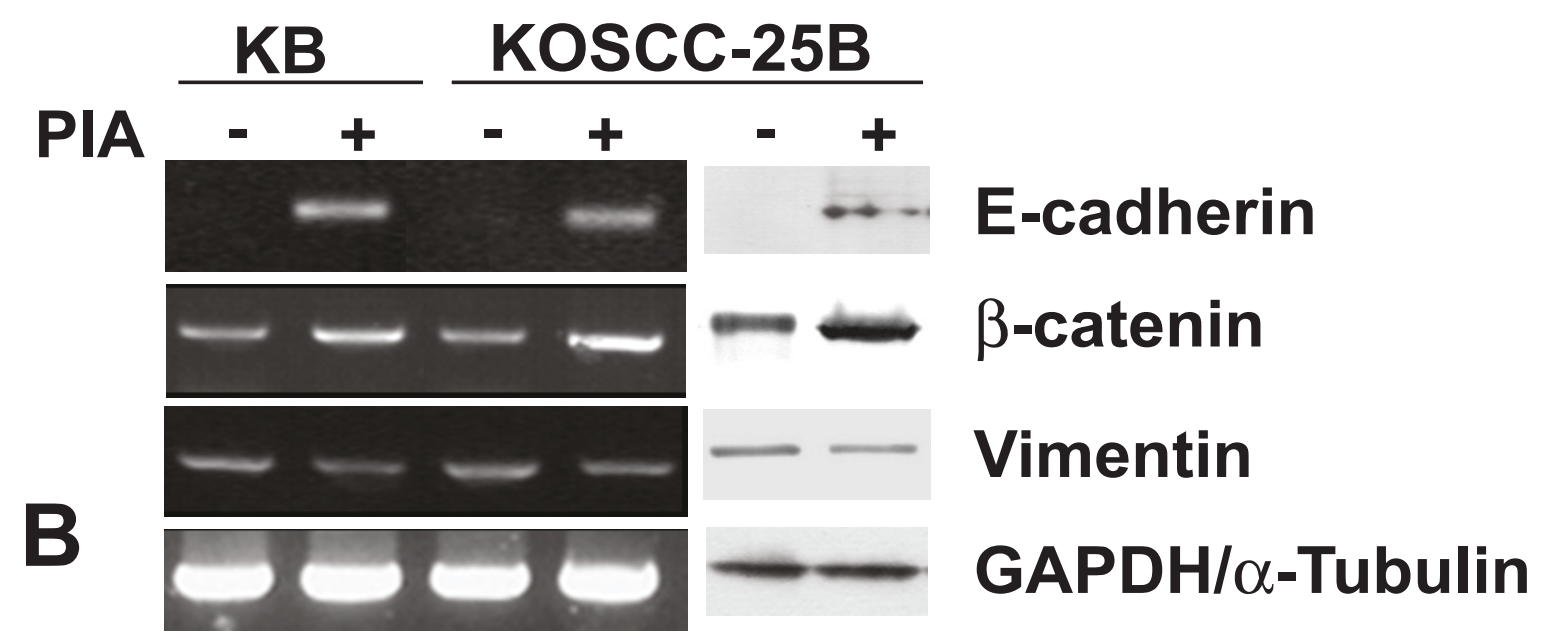

Figure 4

Effects of Akt inhibition on cell morphology and the expression of the epithelial and mesenchymal markers. (A) KOSCC-25B cells had an elongated shape, assuming a fibroblast-like appearance. In contrast, PIA-treated KOSCC-25B cells seemed to restore their epithelial morphology of a polygonal shape. In phalloidin staining, KOSCC-25B cells demonstrated circumferential, cortical actin (blue arrowheads), and actin in elongated filopodia (white arrowheads); however, no actin stress fibers were detected. In contrast, PIA-treated cells revealed an abudance of actin stress fibers (yellow arrowheads). Scale bar: $100 \mu \mathrm{m}$ (black), $20 \mu \mathrm{m}$ (white). (B) Inhibition of Akt activity increased the expression of E-cadherin and $\beta$-catenin, and reduced the Vimentin expression in KB and KOSCC-25B cells. 
- PIA
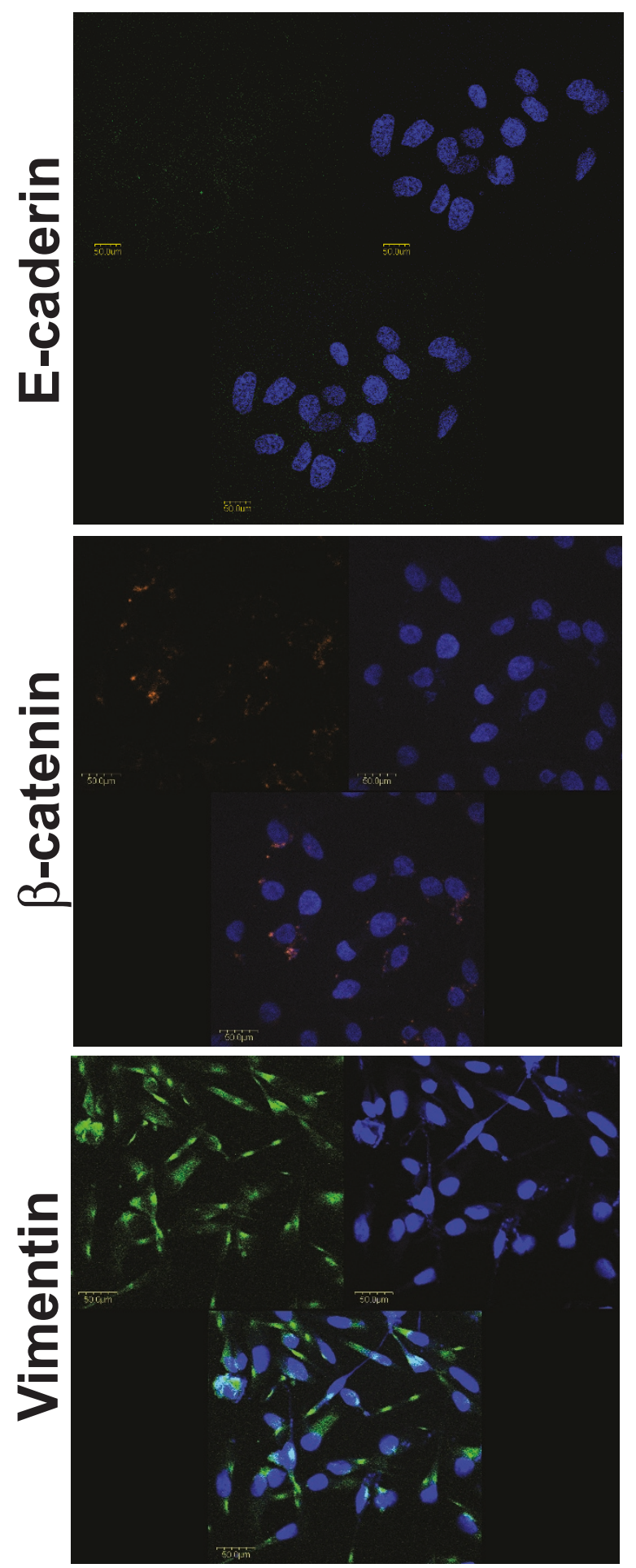

+ PIA
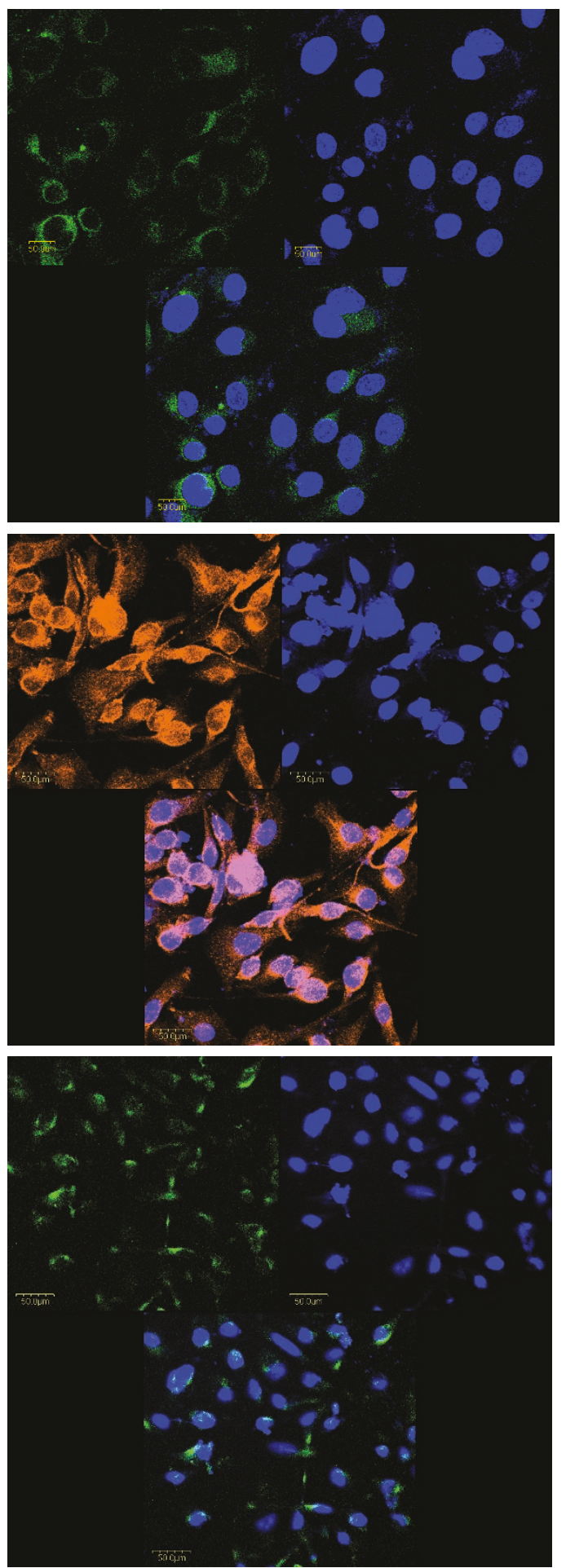

\section{Figure 5}

Effects of Akt inhibition on the localization of the epithelial and mesenchymal markers. The inhibition of Akt activity induced the localization of E-cadherin and $\beta$-catenin, and decreased that of vimentin, as seen in the immunofluorescence analysis. 

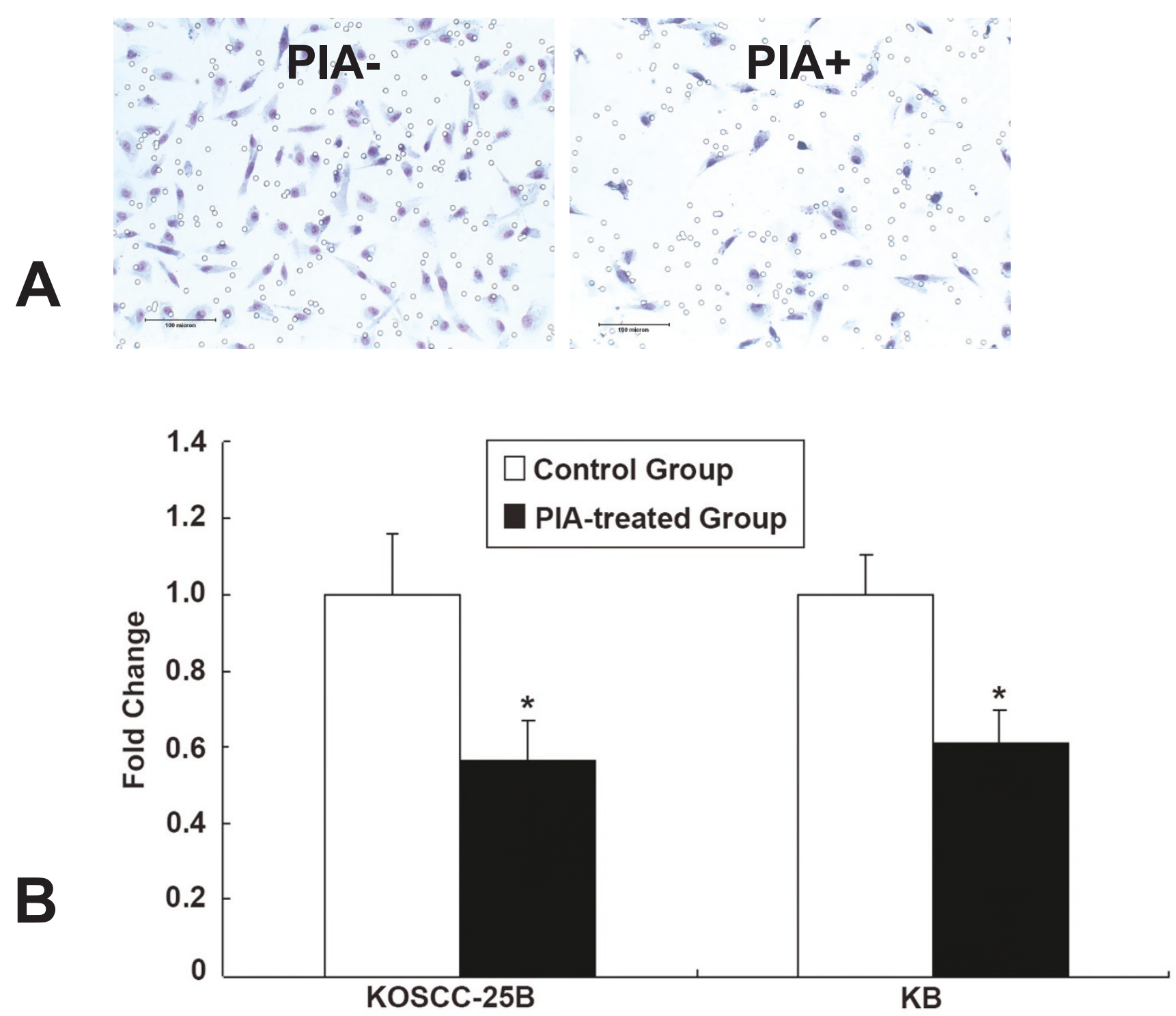

Figure 6

Reduced migratory ability due to Akt inhibition. Photomicrography of control (A) and PIA-treated (B) KOSCC-25B groups in the in vitro migration assay. (C) The numbers of KB and KOSCC-25B cells from the PIA-treated group that migrated through the filter were only $61.1 \%$ and $56.4 \%$ of that in control cells $(P<0.05)$, respectively.

Because OSCC cells engineered to express constitutively active Akt have been known to undergo EMT, we tried to examine whether inhibition of Akt activity could restore epithelial characteristics and deplete mesenchymal features. In the present study, PIA treatment induced the expression and cytoplasmic localization of the epithelial markers (E-cadherin and $\beta$-catenin). In addition, it decreased the vimentin expression and localization, although the change was not as prominent as that in the epithelial markers. Also, the inhibition of Akt activity restored the polygonal epithelial morphology and reduced the migratory ability. This indicates that the inhi- bition of Akt activity could induce the MErT in OSCC cells, and that the gain of epithelial characteristic might earlier or more prominent event in the MErT of the OSCC than the loss of mesenchymal one.

Several EMT-inducing developmental regulators repress Ecadherin transcription via interaction with specific Eboxes of the proximal E-cadherin promoter $[25,26]$. The Snail-related zinc-finger transcription factors (Snail and Slug), the (more distantly related) repressor SIP-1/ZEB-2, and the related Snail family member $\delta$ EF-1/ZEB1 are the most prominent [27-30]. The Snail protein is one of the 
key molecules in the EMT and its expression is inversely correlated with E-cadherin expression in a number of cancers, including OSCC [31-33]. Accordingly, inhibition of Akt activity induced downregulation of EMT-related transcription factor Snail. However, inhibition of Akt activity did not affect the expression level of the SIP-1/ZEB-2. These data suggest that Akt signaling could induce the EMT through activation of Snail, but not SIP-1/ZEB-2, in OSCC cells.

The basic helix-loop-helix transcription factor Twist, a protein known to be essential for initiating mesoderm development during gastrulation, was recently added to the growing list of developmental genes with a key role in E-cadherin repression and EMT induction [34]. Yang et al. [29] demonstrated that knockdown of Twist expression by RNAi in a metastatic mammary tumor cell line prevented lung metastasis, and the high levels of Twist expression seen in $70 \%$ of invasive lobular breast carcinomas, which display many features of EMT, were inversely correlated with E-cadherin expression. However, there have been no reports on the relationship of Twist with the EMT in oral cancer cells. In the present study, inhibition of Akt activity induced downregulation of EMT-related Twist in OSCC cells. To our knowledge, this study is the first description of the participation of Twist in the EMT/ MErT process in oral cancer.

Akt signaling has been deeply studied because Akt plays critical roles in regulating growth, proliferation, survival, metabolism, and other cellular activities [21,35]. Chua et al. [36] showed that NF-кB suppresses the expression of epithelial specific genes E-cadherin and desmoplakin and induces the expression of the mesenchymal specific gene vimentin in breast carcinoma cells. Similarly, Julian et al. [37] reported that activation of NF- $\kappa B$ by Akt upregulates Snail expression and induces EMT in OSCC cells, and expression of the NF-kB subunit p65 is sufficient for EMT induction. We investigated whether it could be possible in the reverse direction, which have been little known. In the present study, inhibition of Akt activity induced the MErT through interaction with NF-kB. Downregulation of NF$\kappa \mathrm{B}$ contributed to MErT. Huber et al. [38] showed that inhibition of NF- $\mathrm{KB}$ signaling prevents EMT in Ras-transformed epithelial cells, while activation of this pathway promotes the transition to a mesenchymal phenotype. Fig. 7 shows a schematic representation of the proposed signaling mechanism that promotes MErT through the inhibition of Akt activity in KB and KOSCC-25B cells. Additional study using NF-kB inhibitors could be needed in order to verify this proposed pathway.

In summary, we demonstrated that Akt inhibition by PIA treatment induced downregulation of Snail and Twist expression, upregulation of E-cadherin and $\beta$-catenin,

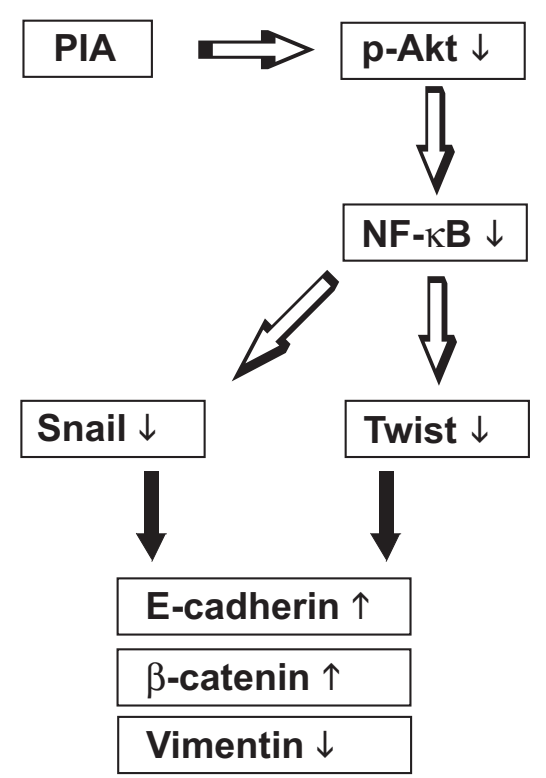

Mesenchymal-to-Epithelial reverting Transition

Figure 7

A schematic representation of the proposed signaling mechanism that promotes MErT through the inhibition of Akt activity in oral cancer cells.

downregulation of vimentin, and reduced cell migration, which led to the MErT in oral cancer cells. The MErT in oral cancer cells seems to be acquired through decreased $\mathrm{NF}-\kappa \mathrm{B}$ signaling. All of these findings suggest that Akt inhibition can induce the MErT through decreased NF- $\kappa B$ signaling and downregulation of Snail and Twist in OSCC cells. A strategy involving Akt inhibition might be a useful therapeutic tool in controlling cancer dissemination and metastasis in oral cancer patients.

\section{Conclusion}

All of these findings suggest that Akt inhibition could induce the MErT through decreased NF- $\mathrm{KB}$ signaling and downregulation of Snail and Twist in OSCC cells. A strategy involving Akt inhibition might be a useful therapeutic tool in controlling cancer dissemination and metastasis in oral cancer patients.

\section{Competing interests}

The authors declare that they have no competing interests.

\section{Authors' contributions}

$\mathrm{KH}$ carried out experiments on the Akt signaling and drafted the manuscript. JK participated in the screening cell lines and migration assay. JH participated in confocal analysis and Western Blot analysis. HY participated in RTPCR analysis. JL and SPH participated in the study design 
and revised the manuscript critically for important intellectual content. SDH conceived of the study, participated in its design and cooperation. All authors read and approved the final manuscript.

\section{Acknowledgements}

This work was supported by grant No. 4-2007-0016 from the Seoul National University Dental Hospital Research Fund.

\section{References}

I. Birchmeier C, Birchmeier W, Brand-Saberi B: Epithelial-mesenchymal transitions in cancer progression. Acta Anat 1996, 156:217-226.

2. Mizunuma H, Miyazawa J, Sanada K, Imai K: The LIM-only protein, LMO4, and the LIM domain-binding protein, LDBI, expression in squamous cell carcinomas of the oral cavity. $\mathrm{Br} J$ Cancer 2003, 88: I543-I548.

3. Lee JM, Dedhar S, Kalluri R, Thompson EW: The epithelial-mesenchymal transition: new insights in signaling, development, and disease. J Cell Biol 2006, I72:973-98I.

4. Christiansen JJ, Rajasekaran AK: Reassessing epithelial to mesenchymal transition as a prerequisite for carcinoma invasion and metastasis. Cancer Res 2006, 66:8319-8326.

5. Testa JR, Bellacosa A: AKT plays a central role in tumorigenesis. Proc Natl Acad Sci USA 200I, 98:10983-10985.

6. Nakayama H, lkebe T, Beppu M, Shirasuna K: High expression levels of $N F \kappa B, I \kappa B \alpha$ and Akt kinase in squamous cell carcinoma of the oral cavity. Cancer 200I, 92:3037-3044.

7. Sun M, Wang G, Paciga JE, Feldman RI, Yuan ZQ, Ma XL, Shelley SA, Jove R, Tsichlis PN, Nicosia SV, et al.: AKTI/PKB $\alpha$ kinase is frequently elevated in human cancers and its constitutive activation is required for oncogenic transformation in NIH3T3 cells. Am J Pathol 200I, 159:43।-437.

8. Brognard J, Clark AS, Ni Y, PDennis PA: Akt/protein kinase B is constitutively active in non-small cell lung cancer cells and promotes cellular survival and resistance to chemotherapy and radiation. Cancer Res 200I, 6 1:3986-3997.

9. Hynes NE, Lane HA: ERBB receptors and cancer: the complexity of targeted inhibitors. Nat Rev Cancer 2005, 5:34I-354.

10. Yamamoto K, Altschuler D, Wood E, Horlick K, Jacobs S, Lapetina EG: Association of phosphorylated insulin-like growth factorI receptor with the $\mathrm{SH} 2$ domains of phosphorylated 3-kinase p85. J Biol Chem 1992, 267: I I337-II 343 .

II. Woodgett JR: Recent advances in the protein kinase B signaling pathway. Curr Opin Cell Biol 2005, I7:150-157.

12. Castillo SS, Brognard J, Petukhov PA, Zhang C, Tsurutani J, Granville CA, Li M, Jung M, West KA, Gills JG, et al.: Preferential inhibition of Akt and killing of Akt-dependent cancer cells by rationally designed phosphatidylinositol ether lipid analogues. Cancer Res 2004, 8:2782-2792.

13. Wells A, Yates C, Shepard CR: E-cadherin as an indicator of mesenchymal to epithelial reverting transitions during the metastatic seeding of disseminated carcinomas. Clin Exp Metastasis 2008, 25:62।-8.

14. Baum B, Settleman J, Quinlan MP: Transitions between epithelial and mesenchymal states in development and disease. Semin Cell Dev Biol 2008, 19:294-308.

15. Lee G, Kim YB, Kim JH, Kim MS, Shin KH, Won YS, Lee JI, Choung $\mathrm{PH}$, Hyun BH, Min BM: Characterization of novel cell lines established from three human oral squamous cell carcinomas. Int J Oncol 2002, 20:1 I5I-II59.

16. Hong JS, Pai HK, Hong KO, Kim MA, Kim JH, Lee Jl, Hong SP, Hong SD: CXCR-4 knockdown by small interfering RNA inhibits cell proliferation and invasion of oral squamous cell carcinoma cells. J Oral Pathol Med 2009, 38:214-219.

17. Herman JG, Graff JR, Myohanen S, Kelkin BB, Baylin SB: Methylation-specific PCR: A novel PCR assay for methylation status of CpG islands. Proc Natl Acad Sci 1996, 93:982I-9826.

18. Lee JK, Kim MJ, Hong SP, Hong SD: Inactivation patterns of p l6/ INK4A in oral squamous cell carcinomas. Exp Mol Med 2004, 36: $165-7 \mid$.

19. Graff JR, Herman JG, Lapidus RG, Chopra H, Xu R, Jarrard DF, Isaacs WB, Pitha PM, Davidson NE, Baylin SB: E-cadherin expression is silenced by DNA hypermethylation in human breast and prostate carcinomas. Cancer Res 1995, 55:5195-5199.

20. Morali OG, Delmas V, Moore R, Jeanney C, Thiery JP, Larue L: IGFII induces rapid $\beta$-catenin relocation to the nucleus during epithelium to mesenchyme transition. Oncogene 2001, 20:4942-4950.

2I. Irie HY, Pearline RV, Grueneberg D, Hsia M, Ravichandron P, Kothari $\mathrm{N}$, Natesan S, Brugge JS: Distinct roles of AktI and Akt2 in regulating cell migration and epithelial-mesenchymal transition. J Cell Biol 2005, I 7 I: 1023-1034.

22. Boyer B, Valles AM, Edme N: Induction and regulation of epithelial-mesenchymal transitions. Biochem Phamacol 2000, 60:1091-1099.

23. Lim J, Kim JH, Paeng JY, Kim MJ, Hong SD, Lee JI, Hong SP: Prognostic value of activated Akt expression in oral squamous cell carcinoma. J Clin Pathol 2005, 58: I 199- I 205.

24. Grille SJ, Bellacosa A, Upson J, Klein-Szanto AJ, van Roy F, Lee-Kwon W, Donowitz M, Tsichlis PN, Larue L: The protein kinase Akt induces epithelial-mesenchymal transition and promotes enhanced motility and invasiveness of squamous cell carcinoma lines. Cancer Res 2003, 63:2172-2178.

25. Peinado H, Portillo F, Cano A: Transcriptional regulation of cadherins during development and carcinogenesis. Int J Dev Biol 2004, 48:365-375.

26. Nieto MA: The snail superfamily of zinc-finger transcription factors. Nat Rev Mol Cell Biol 2002, 3:155-166.

27. Karreth F, Tuveson DA: Twist induces an epithelial-mesenchymal transition to facilitate tumor metastasis. Cancer Biol Ther 2004, 3: 1058-1059.

28. Eger A, Aigner K, Sonderegger S, Dampier B, Oehler S, Schreiber M, Berx G, Cano A, Beug $H$, Foisner R: EFI is a transcriptional repressor of E-cadherin and regulates epithelial plasticity in breast cancer cells. Oncogene 2005, 24:2375-2385.

29. Yang J, Mani SA, Donaher JL, Ramaswamy S, Itzykson RA, Come C Savagner P, Gitelman I, Richardson A, Weinberg RA: Twist, a master regulator of morphogenesis, plays an essential role in tumor metastasis. Cell 2004, I I7:927-939.

30. Rosivatz E, Becker I, Specht K, Fricke E, Luber B, Busch R, Höfler H, Becker KF: Differential expression of the epithelial-mesenchymal transition regulators snail, SIP I, and twist in gastric cancer. Am J Pathol 2002, 161:188I-1891.

31. Cano A, Perez-Moreno MA, Rodrigo I, Locascio A, Blanco MJ, del Barrio MG, Portillo F, Nieto MA: The transcription factor snail controls epithelial-mesenchymal transitions by repressing $\mathrm{E}$ cadherin expression. Nat Cell Biol 2000, 2:76-83.

32. Batlle E, Sancho E, Franci C, Domínguez D, Monfar M, Baulida J, García De Herreros A: The transcription factor snail is a repressor of E-cadherin gene expression in epithelial tumour cells. Nat Cell Biol 2000, 2:84-89.

33. Takkunen M, Grenman R, Hukkanen M, Korhonen M, Garcia de Herreros A, Virtanen I: Snail-dependent and -independent epithelial-mesenchymal transition in oral squamous carcinoma cells. J Histochem Cytochem 2006, 54:1263-1275.

34. Kang Y, Massague J: Epithelial-mesenchymal transitions: twist in development and metastasis. Cell 2004, I I 8:277-279.

35. Larue L, Bellacosa A: Epithelial-mesenchymal transition in development and cancer: role of phosphatidylinositol 3' kinase/AKT pathways. Oncogene 2005, 24:7443-7454.

36. Chua HL, Bhat-Nakshatri P, Clare SE, Morimiya A, Badve S, Nakshatri $H$ : NF-kappaB represses E-cadherin expression and enhances epithelial to mesenchymal transition of mammary epithelial cells: potential involvement of ZEB-I and ZEB-2. Oncogene 2007, 26:71I-724.

37. Julien S, Puig I, Caretti E, Bonaventure J, Nelles L, van Roy F, Dargemont C, de Herreros AG, Bellacosa A, Larue L: Activation of NF-kappaB by Akt upregulates Snail expression and induces epithelium mesenchyme transition. Oncogene 2007, 26:7445-7456.

38. Huber MA, Azoitei N, Baumann B, Grünert S, Sommer A, Pehamberger $\mathrm{H}$, Kraut $\mathrm{N}$, Beug $\mathrm{H}$, Wirth $\mathrm{T}$ : NF- $\mathrm{kB}$ is essential for epithelial-mesenchymal transition and metastasis in a model of breast cancer progression. J Clin Invest 2004, I I 4:569-58I. 